\title{
PREVALENCIA DE ANAPLASMA SPP. EN HUMANOS: REVISIÓN SISTEMÁTICA DE LA LITERATURA ENTRE 2000 Y 2017
}

Recibido: octubre del 2018

Aceptado: mayo del 2019

Juliana Vidal Alzate ${ }^{1}$, Tatiana Acevedo Castro ${ }^{1}$, Dayhanna Osorno Palacio ${ }^{1}$, Johanna Urán Velázquez ${ }^{1}$, Jaiberth Antonio Cardona-Arias ${ }^{2}$

\section{Resumen}

Introducción: La anaplasmosis es una enfermedad febril aguda transmitida por garrapatas. En humanos la especie más importante es Anaplasma phagocytophilum. Objetivo: Metanalizar la prevalencia de anaplasma en humanos reportada en la literatura científica mundial. Métodos: Revisión sistemática de la literatura según las fases Prisma con 14 estrategias de búsqueda en tres bases de datos multidisciplinarias. Se garantizó la reproducibilidad y la evaluación de la calidad metodológica. Los análisis se basaron en proporciones con sus intervalos de confianza del $95 \%$. Resultados: Se sistematizaron 15 estudios publicados entre 2004 y 2017, la mayoría en Polonia (20\%) y China (20\%). El $73 \%$ utilizó IFI y en los demás se empleó PCR anidada o Elisa. La mayoría de grupos de estudio correspondió a sujetos con exposición ocupacional o contacto con animales infectados. La prevalencia con PCR fue de $15,6 \%$ (IC de $95 \%=$ $13,1-18,0$ ), con IFI de $9,3 \%$ (IC de $95 \%=8,5-10,0$ ) y con Elisa de $2,8 \%$ (IC de $95 \%=2,5-3,1$ ). Conclusión: Se reportó una elevada frecuencia de infección y exposición a Anaplasma spp. en humanos, al tiempo que se identificaron puntos importantes para orientar estudios posteriores relacionados con las infecciones cruzadas, las coinfecciones y la circulación del vector.

Palabras clave: Anaplasma phagocytophilum; anaplasmosis; prevalencia; revisión sistemática.

${ }^{1}$ Microbiología y Bioanálisis. Grupo de investigación Salud y Sostenibilidad, Escuela de Microbiología, Universidad de Antioquia.

${ }^{2}$ MyB, MSc en Epidemiología, M.Sc. en Economía Aplicada. Candidato a Doctor en Salud Pública, Universidad de Antioquia. Escuela de Microbiología de la Universidad de Antioquia Correo: jaiberthcardona@gmail.com 


\section{ANAPLASMA SPP. PREVALENCE IN HUMANS: SYSTEMATIC REVISION OF LITERATURE BETWEEN 2000 AND 2017}

Juliana Vidal Alzate ${ }^{1}$, Tatiana Acevedo Castro ${ }^{1}$, Dayhanna Osorno Palacio ${ }^{1}$, Johanna Urán Velázquez ${ }^{1}$, Jaiberth Antonio Cardona-Arias ${ }^{2}$

\section{Abstract}

Introduction: Anaplasmosis is an acute febrille illness transmitted through tick. In humans, the most important species is Anaplasma phagocytophilum. Objective: To meta-analyze the reported prevalence of anaplasma in humans, according to worldwide scientific literature. Method: Systematic revisión of literature according to Prisma phases with 14 strategies in search of three multidisciplinary databases. We guaranteed reproducibility and evaluation of the methodological quality. Analysis were based in proportions with confidence intervals of $95 \%$. Results: 15 research works published between 2004 and 2017 were systematized. Most of them occurred in Poland (20\%) and China (20\%). 73\% used IFI and the rest used PCR. Most of study groups were related to subjects with occupational exposition or contact with the infected animals. The prevalence of PCR was de $15.6 \%$ (CI of $95 \%$ $=13.1-18.0)$, with IFI of $9.3 \%$ (CI of $95 \%=8.5-10.0)$. Conclusion: Studies reported a high frequency of infection and exposition to Anaplasma spp. in humans, while they identified important aspects to orientate later studies related to cross infections, coinfections and the circulation of the vector. 


\section{PREVALÊNCIA DE ANAPLASMA SPP. EM HUMANOS: REVISÃO SISTEMÁTICA DA LITERATURA ENTRE 2000 E 2017}

Juliana Vidal Alzate ${ }^{1}$, Tatiana Acevedo Castro ${ }^{1}$, Dayhanna Osorno Palacio ${ }^{1}$, Johanna Urán Velázquez ${ }^{1}$, Jaiberth Antonio Cardona-Arias ${ }^{2}$

\section{Resumo}

Introdução: a anaplasmose é uma doença febril aguda transmitida por carrapatas. Em humanos, a espécie mais importante é Anaplasma phagocytophilum. Objetivo: meta-analisar a prevalência de anaplasma em humanos relatada na literatura científica mundial. Métodos: revisão sistemática da literatura segundo as fases Prisma com 14 estratégias de busca em três bases de dados multidisciplinares. Foram garantidas a reprodutibilidade e a avaliação da qualidade metodológica. As análises se basearam em proporções com intervalos de confiança de $95 \%$. Resultados: foram sistematizados 15 estudos publicados entre 2004 e 2017, a maioria na Polônia (20\%) e na China (20\%). 73 \% utilizaram IFI e, nos demais, foi empregado PCR aninhado ou Elisa. A maioria de grupos de estudo correspondeu a sujeitos com exposição ocupacional ou contato com animais infectados. A prevalência com PCR foi de 15,6\% (IC de 95\% $=13,1$ 18,0), com IFI de 9,3\% (IC de $95 \%=8,5$ - 10,0) e com Elisa de 2,8 \% (IC de $95 \%=2,5$ - 3,1). Conclusão: foi relatada elevada frequência de infecção e exposição a Anaplasma spp. em humanos, ao mesmo tempo que foram identificados pontos importantes para orientar estudos posteriores relacionados com as infecções cruzadas, com as coinfecções e com a circulação do vector. 


\section{Introducción}

La anaplasmosis es una zoonosis emergente causada por el género Anaplasma (Anaplasmataceae, Rickettsiales), esta es una bacteria intracelular gram negativa que afecta a los humanos y a los animales, y es transmitida por garrapatas del complejo Ixodes ricinus. En humanos, la especie más importante es la Anaplasma phagocytophilum, la cual se presenta en forma de cocos gram negativos, redondeados o elipsoidales, causando anaplasmosis granulocítica humana (AHG). La AHG comparte parcialmente reservorios y vectores con la enfermedad de Lyme (1).

Los síntomas clínicos son inespecíficos, los más comunes son fiebre, dolor de cabeza, malestar y mialgia; además se presentan alteraciones de laboratorio como trombocitopenia, niveles elevados de transaminasas hepáticas y neutropenia. Otras presentaciones clínicas graves incluyen dificultad para respirar, hemorragia, insuficiencia renal o problemas neurológicos (2).

$\mathrm{La}$ anaplasmosis puede ser una enfermedad grave y fatal si no se trata correctamente. El diagnóstico clínico es difícil debido a lo inespecífico de estos síntomas. Los pacientes que reciben tratamiento temprano pueden recuperarse rápidamente, mientras que aquellos que experimentan un curso más grave pueden requerir antibióticos intravenosos, hospitalización prolongada o cuidados intensivos (3).

242 Para la detección del agente, las pruebas más utilizadas son la inmunofluorescen- cia indirecta (IFI) y PCR, por otra parte, su diagnóstico se complementa con criterios clínicos, hallazgos de laboratorio como trombocitopenia, leucopenia y aumento de transaminasas, sumado a los antecedentes de contacto o nexo epidemiológico. Durante la fase aguda de la enfermedad se puede usar PCR o examen microscópico para determinar la infección, ya que estos presentan una mayor sensibilidad en la primera semana de enfermedad. La IFI utiliza el antígeno de anaplasma, realizado en muestras de suero pareadas para demostrar un incremento significativo (cuatro veces) en los títulos de anticuerpos $(3,4)$.

Los primeros casos en Estados Unidos datan de 1987 con múltiples regiones geográficas aptas para la transmisión por la presencia de garrapatas y reservorios como ciervos, cabras, perros y roedores silvestres (3). En este país se han reportado alrededor de $5.000 \mathrm{ca}-$ sos de AHG hasta el 2008, con un alto subregistro y una incidencia anual cercana al 1,4\% de casos por cada millón de personas, con mayor ocurrencia en personas mayores de 50 años (5). Además, según datos más recientes, el número de caso aumentó en un 39\% entre 2016 y 2017 (6).

En Eslovenia desde 1995 y en otros países europeos como Países Bajos, Italia, España, Suecia, Noruega, Austria, Dinamarca, Polonia y Croacia, se ha descrito un bajo número de casos de AHG. En Australia, la seroprevalencia fue del $9 \%$, en Polonia entre $9,6 \%$ y $19,8 \%$, en España de 1,4\%, en Grecia de 7,3\%, en Italia de 5,7\%, en Dinamarca de $21 \%$ y en Alemania entre un $1,4 \%$ y un $2,8 \%$. 
La proporción de pacientes seropositivos aumenta con la edad y es mayor en personas que han sido mordidas por una garrapata. En Bélgica también se han reportado casos con prevalencias de $5,9 \%$ para AHG. Específicamente para A. phagocytophilum en poblaciones expuestas a factores de riesgo la seroprevalencia ha sido entre 11 y $17 \%$ en Suecia, en Dinamarca hasta un $21 \%$ y en Corea de 1,8\% (5-9). Por otra parte, en Suramérica se ha descrito la presencia de anaplasmosis en humanos, mediante estudios serológicos realizados en Argentina y Brasil, sin identificarse la especie involucrada (3).

Lo anterior pone de manifiesto una elevada heterogeneidad en la prevalencia de la infección y la necesidad de sistematizar la evidencia disponible, por lo cual el objetivo de este estudio fue metanalizar la prevalencia de Anaplasma spp. en humanos, reportada en la literatura científica mundial. Las ventajas de este tipo de estudio es que permite el planteamiento de nuevas hipótesis para futuros estudios, la detección de áreas en las que la evidencia científica es escasa, la identificación de posibles fuentes de heterogeneidad y una estimación de mayor precisión y validez externa (10).

\section{Material y métodos}

Tipo de estudio: revisión sistemática de la literatura.

Estrategia de búsqueda y selección de artículos según fases Prisma (Preferred Reporting Items for Systematic reviews and Meta-Analyses) (11).
Identificación: se realizó una búsqueda exhaustiva de la literatura científica publicada en PubMed, Scielo y Lilacs que incluye más de 14 millones de artículos biomédicos desde 1950 y más de mil revistas de América, disponibles desde 1990. Se combinaron los términos Anaplasma o anaplasmosis con los sinónimos que aparecen en los descriptores en Ciencias de la Salud (DeCS) para prevalencia, es decir, frecuencia, ocurrencia, epidemiología, vigilancia, brotes e incidencia, para un total de 14 estrategias de búsqueda diferentes en español y en inglés.

Tamización: en esta fase se aplicaron los criterios de inclusión de tener los términos de búsqueda en título/resumen, ser un estudio observacional descriptivo en humanos como población central y con el reporte explícito de la prevalencia, es decir, la población y el número de positivos; no se aplicaron restricciones de tiempo en la búsqueda y selección, aunque la primera publicación hallada es de la década de los 2000, por lo que se delimitó como ventana de tiempo de este estudio el periodo 2000-2017. Algunas sintaxis usadas en la búsqueda y selección fueron: (Anaplasma[Title]) AND Prevalence[Title/Abstract], (Anaplasmosis[Title]) AND Ocurrence [Title/ Abstract], (ti: (Anaplasma)) AND (ab: (Prevalencia)).

Elección: se excluyeron los estudios que no eran investigaciones originales tipo editoriales o revisiones de tema, estudios con información incompleta como no incluir el nombre de la prueba diagnóstica usada, estudios de caso o series 
de casos con bajo tamaño de muestra (diez o menos).

Inclusión: se realizó una síntesis cualitativa y cuantitativa de los estudios que cumplieron el protocolo anterior, con dichos artículos se realizó una base de datos en un archivo plano de Excel con las variables: título, autores, año de publicación, país de realización, número de personas evaluadas, número de positivos y prueba diagnóstica usada; en algunos estudios fue posible analizar variables adicionales como la especie infectante y la presencia de coinfecciones.

Análisis de reproducibilidad y evaluación de la calidad metodológica: se garantizó la reproducibilidad de la búsqueda y la selección de los estudios por consenso y remisión a un tercero. Para la reproducibilidad de la extracción de la información de los artículos incluidos se hizo un diligenciamiento de la base de datos en Excel, de manera independiente por dos investigadores, donde se halló un índice kappa de 1,00 en las variables cualitativas y un coeficiente de correlación intraclase de 1,00 para las cuantitativas.
Para la evaluación de la calidad metodológica de los estudios se aplicaron los criterios contenidos en la guía Strobe (STrengthening the Reporting of OBservational studies in Epidemiology) para estudios transversales (12), que pese a no ser una guía de calidad metodológica sino editorial, incluye ítems para evaluar la validez interna y externa de los estudios observacionales.

Análisis de la información: la descripción de las variables del estudio se hizo con frecuencias (absolutas y relativas), se construyó un Forest Plot para graficar la prevalencia de infección reportada en cada estudio, así como la prevalencia combinada según la prueba diagnóstica, con sus intervalos de confianza del $95 \%$. En los casos que fue posible, se reportaron las principales coinfecciones.

\section{Resultados}

En la búsqueda inicial se hallaron 1.415 estudios, de los cuales se tamizaron 409 , de estos la mayoría no correspondía a estudios de prevalencia en humanos, por lo que solo se hizo lectura completa de 26 artículos elegibles y se sistematizaron 15 (figura 1). 


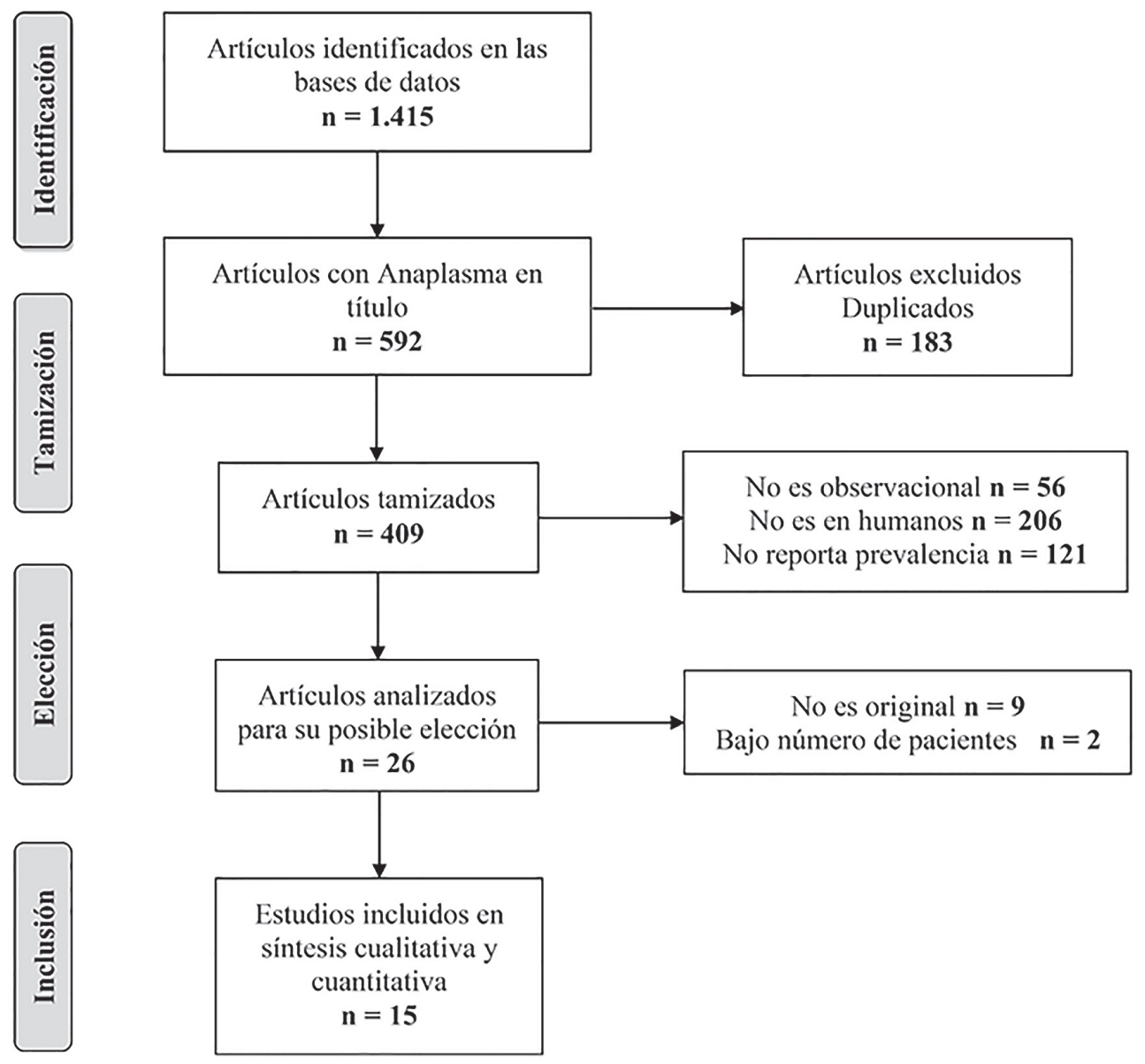

Figura 1. Flujograma de búsqueda y selección de los estudios Fuente: elaboración propia.

Los estudios se publicaron entre 2004 y 2017, la mayoría en Polonia (20\%) y China (20\%), el $73 \%$ empleó IFI y en los demás se utilizó PCR anidada o Eli- sa, y la mayoría de los grupos de estudio correspondió a sujetos con exposición ocupacional o contacto con animales infectados (tabla 1). 
INVESTIGACIONES ANDINA No. 39, Vol. 21

Tabla 1. Descripción de los estudios según año, país, prueba diagnóstica y población

\begin{tabular}{|c|c|c|c|c|}
\hline Autor & Año & País & Prueba & Población \\
\hline Grzeszczuk & 2004 & Polonia & $|F|$ & Trabajador parque \\
\hline Grzeszczuk & 2004 & Polonia & $|F|$ & Trabajador forestal \\
\hline Beltrame & 2006 & Italia & $|F|$ & Contacto garrapatas \\
\hline Máttar & 2006 & Colombia & $|F|$ & $\begin{array}{l}\text { Actividades del } \\
\text { campo }\end{array}$ \\
\hline Stanczak & 2006 & Polonia & $|F|$ & Trabajador forestal \\
\hline Zeman & 2007 & República Checa & PCR anidada & Hospitalizados \\
\hline Abarca & 2008 & Chile & $|F|$ & $\begin{array}{l}\text { Contacto perros y } \\
\text { grupo control sin } \\
\text { contacto }\end{array}$ \\
\hline Graf & 2008 & Estados Unidos & ELISA & Militares \\
\hline Kalinova & 2009 & Eslovaquia & $|F|$ & Sospecha de borrelia \\
\hline Zhang & 2009 & China & $|F|$ & Contacto garrapatas \\
\hline Zhang & 2012 & China & $|F|$ & Trabajo agrícola \\
\hline Hao & 2013 & China & $|F|$ & Exposición forestal \\
\hline Kalinova & 2015 & Eslovenia & $\mathrm{IFI}$ & $\begin{array}{c}\text { Sospecha encefalitis y } \\
\text { un grupo control }\end{array}$ \\
\hline Yi & 2017 & Corea del Sur & PCR anidada & Fiebre y citopenias \\
\hline Keukeleire & 2017 & Bélgica & ELISA & $\begin{array}{c}\text { Trabajadores, } \\
\text { expuestos y donantes } \\
\text { de sangre }\end{array}$ \\
\hline
\end{tabular}

Fuente: elaboración propia.

De manera general, los estudios presentaron una buena calidad metodológica al cumplir $70 \%$ o más de los criterios de la guía Strobe; sin em246 bargo, algunos criterios fueron menos aplicados en los estudios como los relacionados con la declaración de las limitaciones, la fuente de financiación, la discusión de las posibilidades de generalización de los resultados y el control de sesgos de selección e información (figura 2). 


\begin{tabular}{|c|c|}
\hline Criterio & \% de estudios que lo cumplen \\
\hline Título/ Resumen & 100 \\
\hline Fundamentación & 87 \\
\hline Objetivo & 100 \\
\hline Diseño del estudio & 80 \\
\hline Contexto & 87 \\
\hline Participantes & 93 \\
\hline Definición de variables & 80 \\
\hline Fuente de datos & 80 \\
\hline Control de sesgos & 53 \\
\hline Tamaño de muestra & 80 \\
\hline Variables cuantitativas & 73 \\
\hline Análisis estadísticos & 73 \\
\hline Resultados de los participantes & 93 \\
\hline Resultados principales & 73 \\
\hline Análisis adicionales & 60 \\
\hline Discusión de resultados clave & 67 \\
\hline Discusión de otros resutados & 93 \\
\hline Limitaciones & 20 \\
\hline Interpretaciones & 93 \\
\hline Discusión de la generalización & 40 \\
\hline Financiación & 27 \\
\hline
\end{tabular}

Figura 2. Evaluación de la calidad metodológica de los estudios incluidos Fuente: elaboración propia.

En los estudios incluidos se halló una elevada heterogeneidad en la prevalencia reportada, en las investigaciones que usaron IFI osciló entre 6,3\% y 19,8\%; en los dos estudios con Elisa fue entre 2,6\% y $6,5 \%$, mientras que en PCR fue entre $7,1 \%$ y $16,3 \%$. En general se hallaron diferencias estadísticamente significativas en la prevalencia reportada con las tres pruebas, siendo la más elevada en PCR con un $15,6 \%$ (IC de $95 \%=13,1-18,0$ ), seguido de IFI con $9,3 \%$ (IC de $95 \%=$ 8,5 - 10,0) y la más baja con Elisa al re- portarse un 2,8\% (IC de $95 \%=2,5$ - 3,1) (figura 3).

En adición a las técnicas diagnósticas, el tipo de población muestra unas tendencias más altas en población dedicada a actividades de campo-agrícolas, en contacto con garrapatas y sospechas clínicas de enfermedades relacionadas como encefalitis. Aunque se debe aclarar que la heterogeneidad en las poblaciones estudiadas no permitió un resultado de mayor robustez y validez externa. 


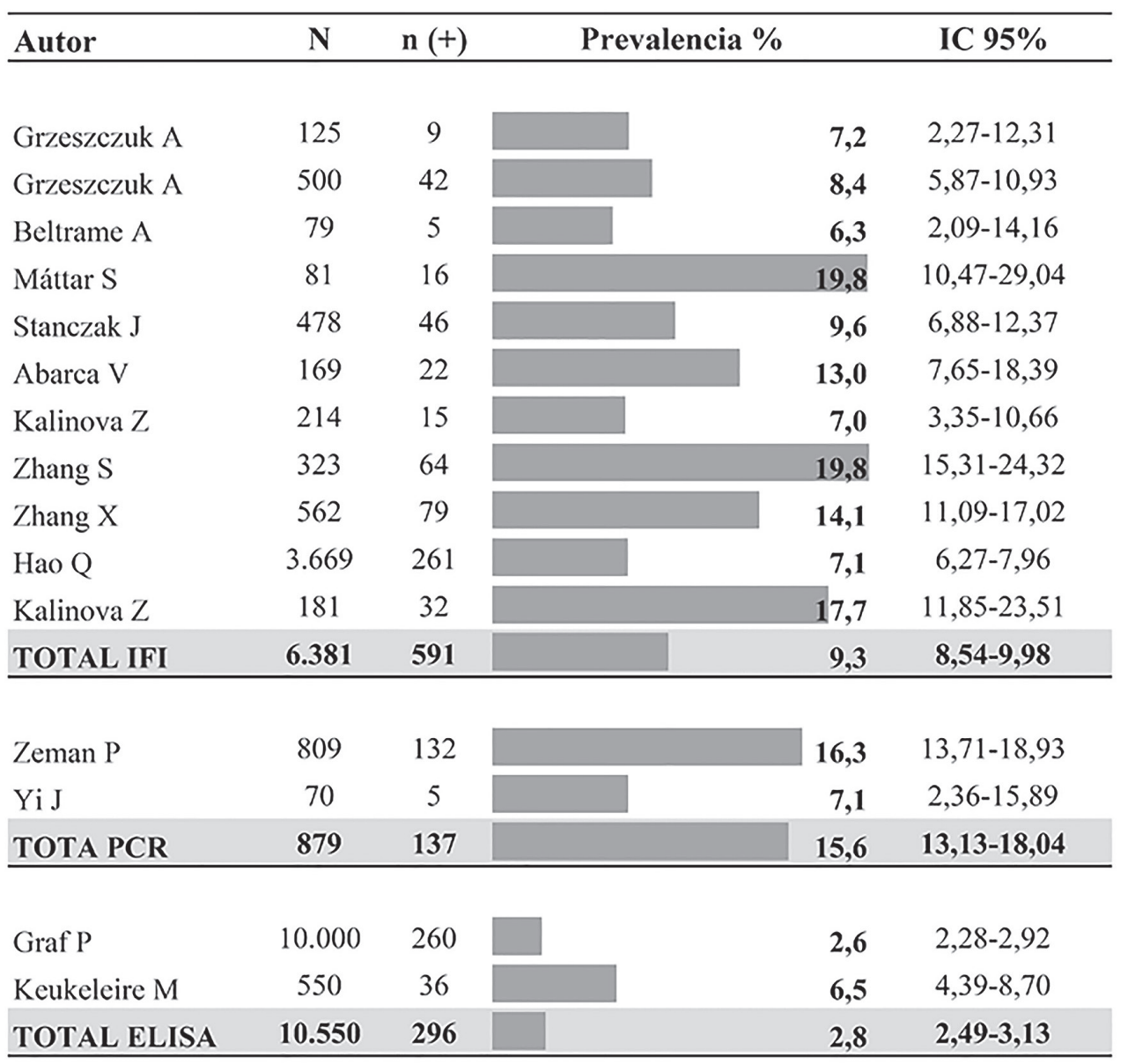

Figura 3. Prevalencia de infección según prueba diagnóstica y estudio Fuente: elaboración propia.

Todos los estudios reportaron como especie infectante a A. phagocytophilum, $y$ en algunos estudios se indican infecciones por otros agentes en la misma población de estudio como Borrelia burgdorferi 21,6\% (13), Bartonella spp. 37,7\%, Coexiella burnetii 26,6\% (16), Ehrlichia chaffeensis 16,4\% (23), Borrelia burgdorferi 10,9\%, Francisella tularensis 2,5\% (27), o co-infección del 0,93\% entre $B$. burgdorferi y A. phagocytophilum (25).

248 Los estudios no resultaron exhaustivos en el reporte de factores asociados; sin embargo, algunos hallaron mayor prevalencia en zonas rurales o con exposición ocupacional $(13,24,27)$; sin diferencias por la edad (13). Otros reportaron una mayor prevalencia en hombres, aunque sin diferencias estadísticamente significativas; así, en el estudio de Grzeszczuk, et al. (13) fue 7,6\% en mujeres y 10,3\% en hombres, Zhang, et al. (22) reportó $16,0 \%$ en mujeres y $22,0 \%$ en hombres y Kalinova, et al. (21) 7,3\% en mujeres y $6,6 \%$ en hombres. 


\section{Discusión}

En este estudio se sistematizaron los hallazgos relacionados con la prevalencia de Anaplasma spp., de acuerdo al año, al país, a la prueba diagnóstica y a la población, donde se encontró que de 1.415 artículos solo 15 pasaron los filtros de búsqueda, esto da indicio de que hasta la fecha son limitados los artículos de prevalencia en esta infección en humanos y casi nulos para el contexto latinoamericano, lo que se suma a su bajo registro en programas de vigilancia de la salud humana y animal.

Las frecuencias halladas fueron 15,6\% con PCR, 9,3\% con IFI y $2,8 \%$ con Elisa, lo que evidencia una heterogeneidad importante entre infecciones activas, pasadas o la tamización de la exposición a Anaplasma spp., así como variaciones entre la prevalencia y la seroprevalencia en función de la validez de la prueba de detección elegida. En tal sentido, estudios previos muestran que para la detección de Anaplasma spp., la identificación de mórulas en las células solo es fuente de sospecha (en adición a los hallazgos clínicos) que generalmente se complementa con serología basada en IFI (28), probablemente por su factibilidad y menor costo en comparación con otras técnicas y sensibilidad (29). Su mayor limitación es la existencia de reacciones cruzadas con algunas especies de Ehrlichia y Anaplasma (28), además de reacciones con otros rickettsiales, como R. rickettsii y R. typhi (4); por lo que su diagnóstico debería complementarse con pruebas moleculares (29).
Para la estimación de la prevalencia en diferentes poblaciones se deben considerar las reacciones cruzadas (28). Un ejemplo claro se da entre la Ehrlichia y la Anaplasma, que pueden presentar una alta tasa de falsos positivos, así como brucelosis, enfermedad de Lyme, enfermedades autoinmunes, entre otros que también presentan interferencia con Anaplasma al momento de hacer el diagnóstico (21).

En este orden de ideas, vale precisar que la escasez de estudios sobre esta infección en humanos implica que los datos de validez diagnóstica de estas pruebas generalmente se basen en poblaciones animales, con valores de sensibilidad analítica de la PCR cercana a 0,0001\% de los eritrocitos infectados (30), por lo que en múltiples estudios se propone como prueba diagnóstica; mientras que Elisa no constituye un buen trazador de exposición y menos de infección, es decir, la tamización y la medición de la exposición podrían basarse en IFI mientras la confirmación de la infección con PCR.

En relación con el diagnóstico de especie, la mayoría refieren $A$. phagocytophilum como principal causante de la AGH (31), aunque esto no descartó la presencia de otras especies en humanos. Por su parte, las coinfecciones demostraron la importancia de estudiar algunos agentes como Borrelia burgdorferi (13, 24, 25, 27), Ehrlichia chaffeensis (23), Bartonella spp., Coexiella burnetii (16) y Francisella tularensis (27). Estos hallazgos podrían atribuirse al hecho de que las garrapatas del complejo del Ixodes sirven como vectores 
competentes para múltiples patógenos que pueden infectar a los humanos incluyendo A. phagocytophilum, Borrelia burgdorferi (el agente de la borreliosis de Lyme) y la Babesia microti (el agente de la babesiosis) (21); lo que daría cuenta de la relevancia clínica, epidemiológica y de salud pública de las intervenciones dirigidas al control de tal vector y del diagnóstico simultáneo de este grupo de infecciones en los territorios en que circulen estas garrapatas, o en aquellos donde se ha demostrado el nexo geográfico (por ejemplo Anaplasma phagocytophilum y Borrelia burgdorferi) o simultaneidad de casos compatibles con AGH, enfermedad de Lyme y otras que presentan manifestaciones similares (2).

Lo anterior también evidencia la importancia de mejorar el estudio del potencial zoonótico de Anaplasma, dada la presencia de esta infección en humanos, bovinos $(15,16)$, caninos $(17,19)$, entre otras especies animales que, de manera indirecta, podrían explicar algunos hallazgos de esta revisión, donde se identificó el mayor riesgo de infección asociado al contacto con animales en zonas rurales o con exposición ocupacional $(13,24,27)$, al tiempo que evidenciaría la necesidad de mejorar los estudios sobre sus reservorios en diferentes poblaciones.
Entre las limitaciones del estudio se destaca el bajo número de artículos, lo que impidió el análisis de algunos subgrupos, así como deficiencias en el reporte de los posibles factores asociados y los resultados de validez diagnósticas de las mediciones de cada estudio. Pese a ello, este estudio demuestra la importancia de revisar el Anaplasma en humanos y la necesidad de estudiar su prevalencia y sus factores de riesgo en poblaciones con las condiciones ecoepidemiológicas adecuadas para su transmisión y endemicidad.

\section{Conclusión}

Se reportó una eleva frecuencia de infección y exposición a Anaplasma spp. en humanos, al tiempo que se identificaron puntos importantes para orientar estudios posteriores relacionados con las infecciones cruzadas, las coinfecciones y la circulación del vector.

\section{Conflicto de intereses}

Ninguno de los autores declara conflicto de intereses para la publicación de este manuscrito.

\section{Financiación}

Recursos en especie de la Universidad de Antioquia. 


\section{Referencias bibliográficas}

1. Pérez R. Garrapatas y anaplasmosis granulocítica humana en Europa. Revisión de la situación en España. Rev Ibérica Parasitol. 2006;66(1):17-29.

2. Schotthoefer A, Hall M, Vittala S, Bajwa R, Frost $\mathrm{H}$. Clinical presentation and outcomes of children with human granulocytic Anaplasmosis. J Pediatr Infect Dis Soc. 2017;7(2):e9-e15.

3. Centers for Disease Control and Prevention. Signs and symptoms Anaplasmosis [Internet]. 2018 [citado 2018 sept. 11]. Disponible en: https://www.cdc.gov/ anaplasmosis/symptoms/index.html

4. Oteo J, Brouqui P. Ehrlichiosis y anaplasmosis humana. Enferm Infecc Microbiol Clín. 2005;23(6):331-92.

5. Jin H, Wei F, Liu Q, Qian J. Epidemiology and control of human granulocytic anaplasmosis: a systematic review. Vector Borne Zoonotic Dis. 2012;12(4):269-74.

6. Centers for Disease Control and Prevention. Anaplasmosis: Epidemiology and Statistics [Internet]. 2019 [citado 2019 febr. 27]. Disponible en: https:// www.cdc.gov/anaplasmosis/stats/index. html

7. Hing M, Van den bossche D, Lernout T, Cochez C, Pirnay J, Heuninckx W. Prevalence of Anaplasma phagocytophilum in humans in Belgium for the period 2013-2016. Acta Clinical Belgica. 2018:16. doi:10.1080/17843286.2018.1491928. [Epub ahead of print].

8. Hennigsson A, Wilhelmsson P, Gyllemark $P$, Kozak M, Matissek A, Nyman D, et al. Low risk of seroconversion or clinical disease in humans after a bite by an Anaplasma phagocytophilum-infected tick. Ticks tick Borne Dis. 2015;6(6):787-92.

9 Skarphédinsson S, Søgaard P, Pedersen C. Seroprevalence of human granulocytic ehrlichiosis in high-risk groups in Denmark. Scand J Infect Dis. 2001;33(3):206-10.

10. Cardona J, Higuita L, Ríos L. Revisiones sistemáticas de la literatura científica: la investigación teórica como principio para el desarrollo de la ciencia básica y aplicada. Bogotá: Ediciones Universidad Cooperativa de Colombia; 2016.

11. Hutton B, López F, Moher D. The PRISMA statement extension for systematic reviews incorporating network meta-analysis: PRISMA-NMA. Medicina Clínica. 2016;147(6):262-6.

12. Von E, Altman D, Egger M, Pocock S, Gotzschee P, Vandenbroucke J, et al. Declaración de la Iniciativa STROBE (Strengthening the Reporting of Observational studies in Epidemiology): directrices para la comunicación de estudios observacionales. Gac Sanit. 2008;22(2):144-50.

13. Grzeszczuk A, Puzanowska B, Miegoć $H$, Prokopowicz D. Incidence and prevalence of infection with Anaplasma phagocytophilum Prospective study in healthy individuals exposed to ticks. Ann Agric Environ Med. 2004;11(1):155-7.

14. Grzeszczuk A, Stańczak J, Kubica-biernat B, Racewicz M, Kruminis-Łozowska W. Human anaplasmosis in north-eastern Poland: seroprevalence in humans and prevalence in Ixodes ricinus ticks. Ann Agric Environ Med. 2004;11(1):99-103.

15. Beltrame A, Ruscio $M$, Arzese A, Rorato G, Negri C. Human Granulocytic Anaplasmosis in Northeastern Italy. Century of Rickettsiology. 2006;1078(1):106-9.

16. Máttar S, Parra M. Detection of antibodies to Anaplasma, Bartonella and Coxiela in rural inhhabitants of the Caribbean area of Colombia. Revista MVZ Córdoba. 2006;11(2):781-9. 
17. Stanczak J, Grzeszczuk A. Seroprevalence of Anaplasma phagocytophilum among forestry rangers in Northern and Northeastern Poland. Century of Rickettsiology. 2006;1078(1):89-91.

18. Zeman P, Pazdiora P, Chmelik V, Januska J, Sedivy K. Epidemiological survey of tick-borne encephalitis virus and Anaplasma phagocytophilum co-infections in patients from regions of the Czech Republic endemic for tick-borne diseases. Wiener klinische Wochenschrift. 2007;119(17-18):538-43.

19. Abarca K, López J, González P, Dabanch J, Torres M. Seroepidemiological evidence of human exposure to Anaplasma sp in Santiago, Chile. Rev Chil Infectol. 2008;25(5):358-61.

20. Graf P, Chretien J, Ung L, Gaydos J, Richards A. Prevalence of seropositivity to spotted fever group rickettsiae and Anaplasma phagocytophilum in a large, demographically diverse US sample. Clinical Infectious Diseases. 2008;46(1):70-7.

21. Kalinova Z, Halanova M, Cislovoka L, Sulinova Z, Jarcuska P. Occurrence of IgG antibodies to Anaplasma phagocytophilum in humans suspected of Lyme borreliosis in eastern Slovakia. Ann Agric Environ Med. 2009;16(2):285-88.

22. Zhang S, Hai R, Li W, Li G, He J. Seroprevalence of Human Granulocytotropic Anaplasmosis in Central and Southeastern China. Am J Trop Med Hyg. 2009;81(2): 293-5.

23. Zhang $X$, Zhang L, Li W, Wang S, Sun $Y$, Wang $Y$, et al. Ehrlichiosis and Zoonotic Anaplasmosis in Suburban Areas of Beijing, China. Vector-Borne Zoonotic Dis. 2012;12(11):932-37.

24. Hao Q, Genz Z, Hou X, Tian Z, Yang $X$. Seroepidemiological investigation of lyme disease and human granulocytic Anaplasmosis among people living in forest areas of eight provinces in China. Biomed Environ Sci. 2013;26(3):185-9.

25. Kalinová Z, Halánová M, Cisláková $L$, Juriš $P$, Čechová $L$. Occurrence of antibodies to Anaplasma phagocytophilum in patients with suspected tick-borne encephalitis. Ann Agric Environ Med. 2015;22(3):409-11.

26. Yi J, Kim K, Ko M, Lee E, Choi S. Human granulocytic Anaplasmosis as a cause of febrile illness in Korea since at least 2006. Am J Trop Med Hyg. 2017;98(4):777-82.

27. De Keuheleire $M$, Vanwambeke $S$, Cochez C, Heyman P, Fretin D, Deneys $\mathrm{V}$, et al. Seroprevalence of Borrelia burgdorferi, Anaplasma phagocytophilum, and Francisella tularensis Infections in Belgium: results of three population-based samples. Vector-Borne Zoonotic Dis. 2017;17(2):108-15.

28. Alleman R, Couto G. Análisis para enfermedades transmitidas por garrapatas: cómo y cuándo. [Internet] 2018 [citado 2017 sept. 11]. Disponible en: https://vet. osu.edu/sites/vet.osu.edu/files/legacy/ documents/pdf/vmc/greyhound/spanish/ Garrapatas.pdf

29. Silaghi C, Santos A, Gomes J, Christova I, Matei I. Pautas para la detección directa de Anaplasma spp en diagnóstico y estudios epidemiológicos. Enfermedades transmitidas por vectores y zoonóticas. $2017 ; 17(1): 12-22$.

30. Organización Mundial de Sanidad Animal OIE. Anaplasmosis bovina. [Internet] 2015 [citado 2017 sept. 11]. Disponible en: http://www.oie.int/fileadmin/Home/esp/ Health_standards/tahm/2.04.01_Anaplasmosis_bovina.pdf

31. Dumler J, Choi K, García J, Barat N, Escorpio D. Human Granulocytic Anaplasmosis and Anaplasma phagocytophilum. Emeg Infect Dis. 2005;11(12):1828-34. 